\title{
Adult size and mate choice in seaweed flies (Coelopa frigida)
}

\author{
K. D. Pitafi, \\ R. Simpson, \\ J. J. Stephen and \\ T. H. Day
}

Department of Genetics, Queens Medical Centre, University of Nottingham, Nottingham NG7 2UH, U.K.

The willingness to mate of pairs of seaweed flies (Coelopa frigida) was measured using a stock known not to exhibit female mate choice with respect to a chromosomal inversion. Mating success was strongly correlated with the size of the female, but not at all with male size. Mating success was not associated with the size difference between the male and female in a pair, except when the male was considerably larger than the female, when mating success was reduced. The components of mating behaviour were quantified during slow-playback of video recordings. Both the mount rate and the proportion of mounts ending in female rejection were positively correlated with female size, and a strong negative correlation was found between female size and the rate of male dismounting. This lower rate of dismounting from large females may be the consequence of a male preference for large females and could account for their greater mating success. The higher rejection rate exhibited by large females, particularly of males much smaller than themselves, may be the manifestation of female choice for large males. Both sexes appear to prefer large mates. In trials involving many animals male mate choice is either weaker or is masked by other effects. The evolutionary significance of male mate choice and its interactions with other components of mating behaviour are discussed.

\section{INTRODUCTION}

Size has many profound effects on the biology of animals. It is not only associated with development and survival, but influences many aspects of mating and reproduction. Among the insects alone, where the effects are particularly pronounced, there is considerable evidence that large males have a mating advantage-in various species of Drosophila (Monclus and Provosti, 1971; Partridge et al., 1987a, b), Dryomyza anilis (Otronen, 1984), Musca domestica (Baldwin and Bryant, 1981), Scatophaga stercoraria (Borgia, 1982), Chauliognathus pennsylvanicus (McCauley and Wade, 1978), Brentus anchorago (Johnson, 1982), Plecia nearctica (Thornhill, 1980), Centris pallida (Alcock, 1979) and Conocephalus nigropleurum (Gwynne, 1982). This widespread correlation of male body size with mating success can variously be attributed to large males being superior in male-male competition and to females preferring to mate with larger males, although other factors such as greater fecundity and longevity may also play a role.

As far as female size is concerned, greater size is often associated with higher fecundity, but there are relatively few examples of male preference for large females (but see Manning, 1975; Gwynne, 1981). Trivers (1972) has suggested that this is a consequence of the differential investment by the two sexes in gametes, mating and parental care.

The seaweed fly, provides an example of how complex the associations can be of size with mating behaviour. Differential male mating success exists between chromosomal inversion genotypes, known to be a major genetic determinant of size (Butlin et al., 1982; Day et al., 1987). Populations also exhibit positively assortative mating with respect to size (Day and Butlin, 1987). In addition there are differences associated with size in adult fecundity and longevity (Butlin and Day, 1985). Recent analyses of mating behaviour (Crocker and Day, 1987; Engelhard et al., 1989) have suggested that female seaweed flies are choosing their mates on the basis of the male's inversion genotype, and that there might also exist an element of male mate choice. The work reported here is concerned with this latter possibility.

We have studied the effect of size on mating success and behaviour under conditions that excluded male-male competition, and should have 
reduced the influence of female choice to a minimum. We first determined the effects of male and female size on mating success, and then explored the reasons for these effects.

The mating success of pairs of animals was strongly associated with the size of the female, but apparently not at all with the male's size. This seems to be a consequence of males being more likely to dismount from small females. We suggest that male choice is operating and that males prefer to mate with large females. Trials were also carried out involving many females. The association between mating success and female size is still observed, but it is either weaker, or is masked by other interactions.

\section{MATERIALS AND METHODS}

The SMI-C laboratory stock of $C$. frigida originated from a natural population at St. Mary's Island on the north-east coast of England. By a series of pair matings over several generations, a stock was derived that was homozygous for the $C$ allele at the alcohol dehydrogenase (Adh) locus on chromosome I. Females carrying the $A d h-C$ allele have previously been shown not to exhibit female choice with respect to the males' Adh genotype (Engelhard et al., 1989).

Cultures were maintained as described by Day and Buckley (1980) with the modification that the sole food source was Fucus serratus and $F$. vesiculosus freshly harvested from the sea. Adults were collected within 18 hours of eclosion and males and females stored separately at $4^{\circ} \mathrm{C}$ (Crocker and Day, 1987). When required for trials, animals were transferred to fresh seaweed at $26^{\circ} \mathrm{C}$ overnight. Checks for virginity showed that in no case had any female been fertilized.

For mating trials involving one male and one female, the adults were placed in pots $(40 \mathrm{~mm}$ diameter $\times 45 \mathrm{~mm}$ deep) half filled with finely minced seaweed. After 20 hours the male was removed and the female left for a further two days during which time each pot was checked for the presence of larvae. Independent experiments have shown that if a female had not laid fertile eggs within two days, she would not produce progeny at all.

The size of each male and female was estimated by measuring the wing length--the distance from a prominent supra-alar bristle to the posterior margin of the upper wing in the folded position (Butlin et al., 1982). Wing length is known to be strongly correlated with most other bodily dimensions.

Trials with one male and 20 females were carried out in larger pots $(75 \mathrm{~mm}$ diameter $\times 70 \mathrm{~mm}$ deep but, with this exception, all other details were the same as for the " $1+1$ " trials.

The video recording of mating behaviour was as described by Day et al. (1989) except that trials were of 45 minutes duration.

\section{RESULTS}

\section{Mating success in pair trials}

The willingness to mate of pairs of virgin adults was measured using a laboratory stock homozygous for the $A d h-C$ allele. Females of this genotype have previously been shown not to be discriminating in their choice of mate (Engelhard et al., 1989). Since only one male was present, there was obviously no opportunity for male-male competition. The criterion for mating was the subsequent production of larvae. Each trial yielded three pieces of information-size of the male, size of the female, and whether or not the pair had mated to produce progeny. The analysis was based on 1024 such trials, and was directed towards answering three questions.

\section{(i) Is mating success associated with female size?}

Pairs were grouped into categories according to the size of the female, such that every group included 20 trials. (A consequence of this is that the groups do not all span the same size range, particularly at the extremes of the distribution.) Within each group the proportion of pairs that mated was calculated and it is this proportion that is used as the measure of mating success. The relationship between female size and mating success is shown in fig. 1 with each point representing a group of 20 trials. There is a highly significant positive correlation between the two variables $(r=$ $0.527, n=50 ; P \ll 0.001)$. It appears that the willingness of two flies to mate strongly depends on the size of the female.

\section{(ii) Is mating success associated with male size?}

A similar analysis was carried out, this time grouping the trials according to the size of the male. No association was observed between mating success and male size $(r=0.007, n=50 ; P=0.96)$. 


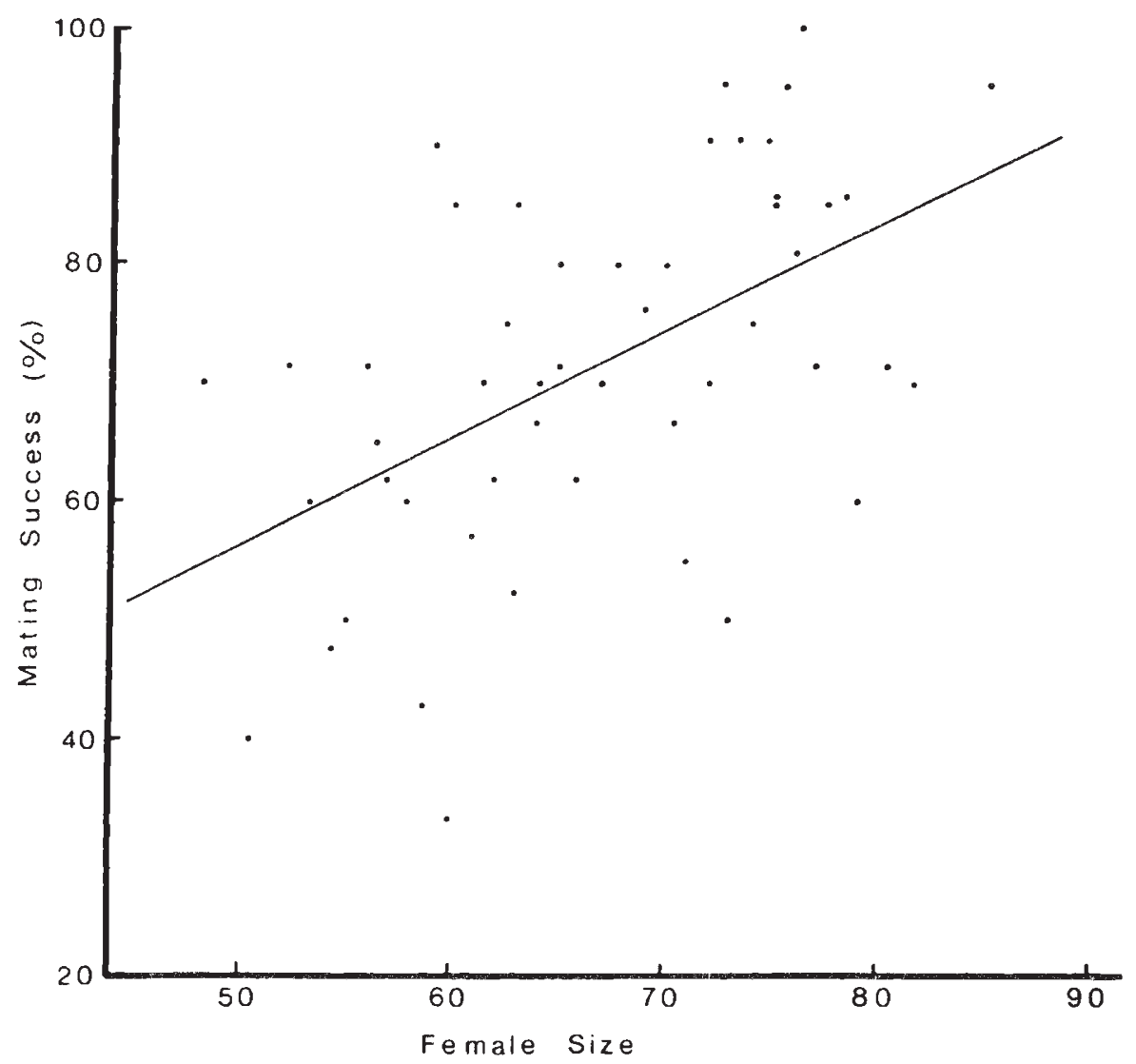

Figure 1 Relationship between mating success and female size. Each point is calculated from 20 trials and represents the percentage of those trials that resulted in the production of progeny. Female sizes are expressed in graticule units $(1 \mathrm{unit}=0.063 \mathrm{~mm})$.

(iii) Is mating success associated with the malefemale size difference?

For several species, including $C$. frigida, evidence exists for positive assortative mating with respect to size (Davies and Halliday, 1977; Johnson, 1982; McLain, 1982; Arak, 1983; Cooke and Davies, 1983). If such assortment is manifest in the willingness to mate of pairs of adults, we might expect mating success to be highest when the flies are of similar size, or at some intermediate relative size between the two, and for the success to decline away from such an optimum. This prediction was tested by calculating for each trial the difference in sizes between the male and female (always male minus female). The relationship between mating success and size difference is shown in fig. 2. Over most of the range of size difference, mating success appears to be fairly constant, but when the male is considerably larger than the female-more than about 50 per cent larger - the mating success declines. Except at this extreme, willingness to mate does not appear to be influenced by the relative sizes of the male and female. Indeed, there may even be a slight hint that there is an unwillingness to mate when the the animals are of similar size. These results do not lend support to the idea that animals have the highest mating success when encountering a potential mate of similar size.

\section{Analysis of mating behaviour}

The principal conclusion from the pair trials was that mating success is strongly associated with female size. We next attempted to identify at what stage in the mating process the size of the female influences eventual success. Mating behaviour in C. frigida seems to be very straightforward (Day et al., 1989). The male mounts the female with no obvious prior courtship behaviour. The female may then reject him using her legs and wings, or the male may dismount with no apparent provocation. If neither happens, then the genitalia engage 


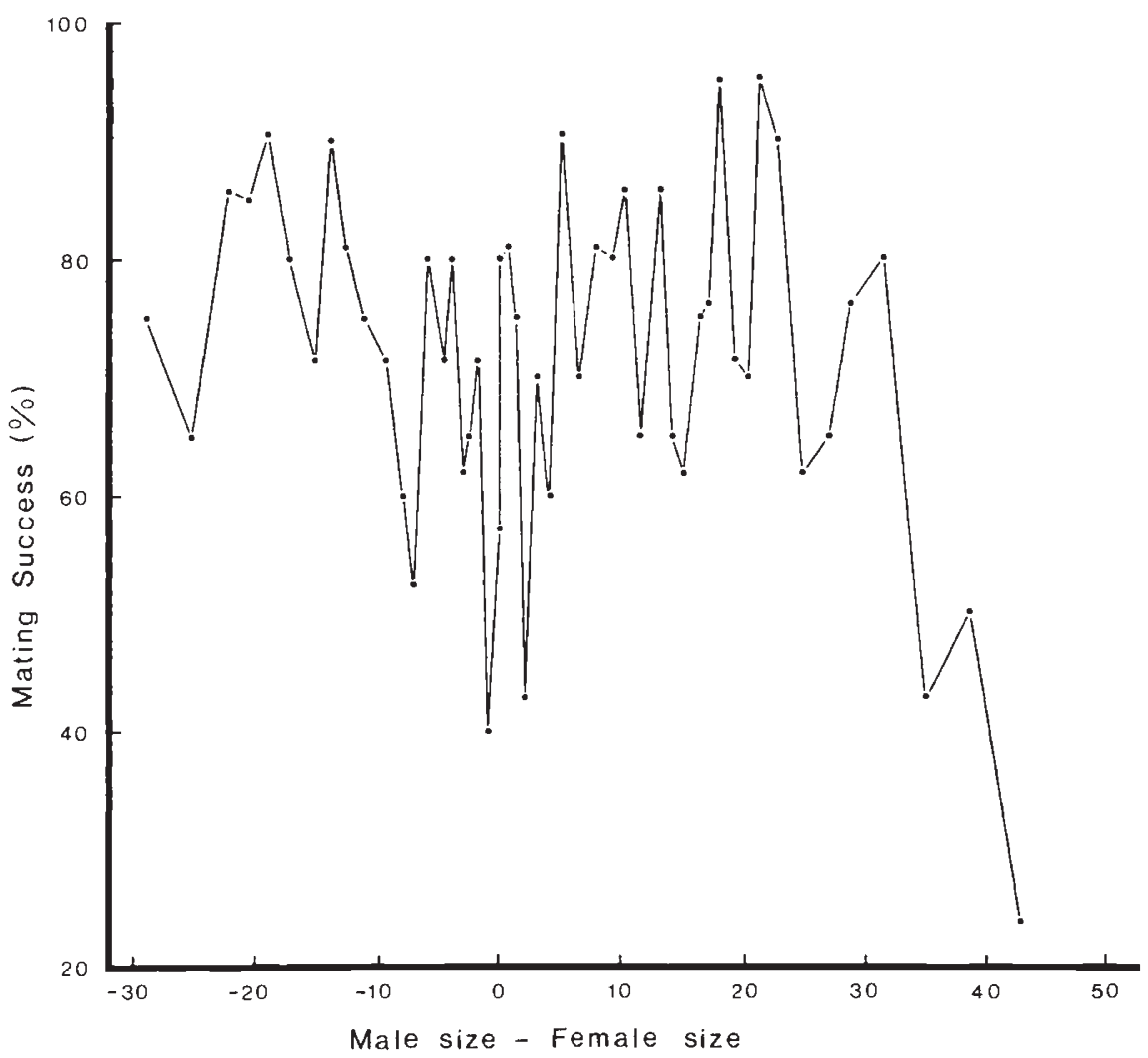

Figure 2 Relationship between mating success and size difference (male size minus female size). The calculation of mating success and the units of size are the same as in fig. 1.

and they remain mounted usually for about one minute.

There are at least three reasons why mountings might more commonly become prolonged when the female is large. Perhaps large females are somehow more attractive to males-they might be more readily seen by the male, or they might emit some chemical in larger amounts. In this case we should expect the number of mounts initiated to increase with increasing female size. Alternatively large females might more rarely reject males. Thirdly, males might dismount large females less frequently than small ones, or of course, a combination of all three effects might be happening.

In order to distinguish these possibilities males and females of various sizes were observed, and the components of their behaviour quantified during slow play-back of video recordings. In each trial one male and two females were used. The analyses, based on 20 such trials, were of two types. The behaviour of the two females in each trial were compared using Wilcoxon's ranked-pairs test. In addition, any general association of female size with other variables was sought using Spearman's rank correlation. This disregards the fact that the females were being observed two at a time in each trial but in acknowledgement of the fact that the number of truly independent observations was 20 , significance levels have been calculated with 20 degrees of freedom. Several questions were asked of the data.

(i) Is the larger female in a pair mounted more often than the smaller female? The answer appears to be a clear yes (Wilcoxon $T_{\mathrm{s}}=9, n=20 ; P \ll 0.001$ ). Over all trials, each large female was, on average, mounted once every 1.2 mins., whereas the small female was mounted approximately every $4 \cdot 4$ mins.

(ii) Does the number of times a female is mounted correlate with her size, regardless of the other female present? Again, there is a clear yes (Spearman's $R=0.707, \quad n=20 ; \quad P \ll 0.001)$. This correlation indicates that the chances of a female being mounted is related to her size, and consequently that 
there must be some sensing at a distance by the male. The nature of the stimulus whether visual, olfactory or of some other type, is not yet known.

(iii) Does the larger female reject more or less than the smaller one? By calculating the proportion of mounts ending in female rejection for each female, it was shown that the larger females exhibited a higher rejection rate $\left(T_{\mathrm{s}}=32, n=19 ; P=0.009\right)$.

(iv) Is the rejection rate correlated with female size? A positive correlation exists with female size ( $R=$ $0.542, n=20 ; P<0.01)$. Rejection rate is also negatively correlated with male size $(R=-0 \cdot 486$, $P<0.025$ ), but by far the strongest correlation is a negative one with the male-female size difference, calculated as male size minus female size $(R=-0.66, P \ll 0.001)$. If female rejection is an expression of female choice, the females appear to prefer large males, particularly those that are large relative to themselves. While there is considerable evidence for female choice in seaweed flies (Crocker and Day, 1987; Day and Butlin, 1987; Engelhard et al., 1989) the preferred character was shown to be the Adh genotype of the male. The present results provide the first evidence that female seaweed flies also choose males on the basis of their size. Note that we cannot conclude that large females are more discriminating. Their greater rejection rate may simply be a consequence of the fact that large females are more likely to have been paired with a male that is perceived as being. small. Quite apart from female choice, the fact that large females exhibit a higher rejection rate, means that the greater mating success enjoyed by large females cannot be a consequence of differences in female rejection rate. This aspect of mating behaviour would tend to reduce the mating success of large females, at least in pair trials.

(v) Is the larger female dismounted less often than the smaller one? When the proportion of mounts ending in a dismount was calculated for the two females in each trial, it was seen that the larger female is dismounted significantly less often than the smaller one $\left(T_{\mathrm{s}}=27, P<0.01\right)$. In one of the trials the smaller female was only mounted once and was not dismounted. If this trial is omitted from the analysis the difference between the larger and smaller female becomes strikingly more significant.

(vi) Is the male dismount rate generally correlated with female size? Even with the exceptional trial included in the analysis, there is a strong negative correlation $(R=-0.628, \quad P<0.005)$. It would appear that males dismount less often from large females than from small ones, an observation which we provisionally interpret as the consequence of male choice with respect to female size. It is worth remembering that mounts can have one of three outcomes-female rejection, male dismount or a prolonged mount. The negative correlation between female size and dismount rate is not therefore the trivial consequence of the positive correlation with female rejection. In passing, we may also point out that there is no association between dismount rate and male size $(R=0.354$, $P=0 \cdot 13$ ). Expressed loosely, small males do not seem to be more impressed by large females than do large males.

These trials may be summarised as follows. Large females are mounted often and usually not dismounted, both of which effects would increase the number of prolonged mounts. This number is likely to be reduced by the relatively high rejection rate shown by large females. In practice these effects combine so that large females do indeed engage in more prolonged mounts than small ones. On average each large female spent over five minutes in mating, whereas the smaller females spent just over one minute, and if one exceptional trial is disregarded, the average for the remaining 19 small females was less than 30 seconds. This must mean that the opportunity for insemination is much greater for large females, and it is the likely reason why large females exhibited higher mating success in the pair trials reported above.

\section{Trials, involving many animals}

It was of interest to determine whether the apparent male preference for large females observed in laboratory trials also operates under more natural conditions. It has proved very difficult to study mating in seaweed flies in the field. Mating is known to occur within large littoral deposits of decomposing seaweed and in the presence of many other adults-probably several thousands. Consequently an attempt was made to simulate more natural conditions in the laboratory.

One male was allowed access to 20 virgin females, ten of which were distinctly larger than the rest. After 20 hours the females were isolated and each classified as mated or not on the basis of whether they produced progeny. The sizes of the mated and unmated females were then compared in each of 26 trials. In eight trials the mated females were significantly larger than the unmated ones. However, because 26 comparisons were made, the significance levels were modified using 
the method of Sidak (see Sokal and Rohlf, 1981). Taking into account multiple tests in this way, only two trials can be taken as significant, one at the 3 per cent level, and the other at the 2 per cent level. This hardly constitutes strong evidence for large females having greater mating success than small ones. Nevertheless, we were impressed by the consistency of this phenonomenon. In 23 of the 26 trials the mated females were larger than those unmated, which of course is a highly significant departure from randomness $\left(\chi_{1}^{2}=15 \cdot 4 ; P<0 \cdot 001\right)$.

\section{DISCUSSION}

The mating success of pairs of seaweed flies is strongly associated with female size, but not at all with male size. These results contrast with those of Day et al. (1987) who found no effect of female size but a strong effect of male size on mating success. There are at least two possible reasons for this discrepancy.

The earlier results derived from population cages in which the adults were allowed to eclose and then mate with whom they chose, and as often as they wished. Under these conditions large males would be expected to out-compete smaller males in the multiple encounters that are likely to have occurred (Engelhard et al., 1989). Furthermore, the earlier eclosing females are the smallest and this may have allowed small females greater opportunity for mating. The opposing effects of male choice for large females, and the more extended availability of small females for mating may have combined to yield no apparent association of female size with mating success. This changing availability of both females and males might also have generated the assortment in mating seen in the earlier study, but not observed in the pair trials.

A second difference between the experiment reported here and those of Day et al. is the nature of the animals themselves. The earlier experiments used populations segregating at the Adh locus, whereas only animals homozygous for the $A d h-C$ allele were used in the present study. Such a small difference may not be trivial. The absence of female choice in the SMI-C line may result in male size being irrelevant, and allow the consequences of male choice to be observed.

The sequence of events during mating make such an interpretation plausible (Day et al., 1989). Female rejection usually occurs within seconds of the male mounting the female, whereas dismounting by the male is often seen 5-20 seconds after mounting, although it can be virtually instan- taneous. It follows that if the female does reject, the opportunity may not be available for the male to exercise any choice. This means that male choice will usually only be observable in laboratory trials in the absence of female choice: however, it does not mean that male choice is of no consequence in natural populations.

Let us now consider the possible evolutionary significance of male mate choice. Trivers (1972) suggested that when there is a pronounced disparity in reproductive investment, the sex investing more will exhibit mate discrimination. There is no evidence whatsoever for parental care in seaweed flies, so we need only consider the cost of gametic production and of mating. There can be little doubt that the female investment in eggs is considerable. A female that has laid all her eggs is approximately 25 per cent lighter than her eclosion weight (Pitafi, unpublished results). However, a comparable weight loss is seen in males. Furthermore, a male that has mated with several females in quick succession loses his ability to inseminate further females. Whether this is because his sperm supply has become exhausted, or because he no longer has sufficient accessory gland fluid is not yet clear. Indeed the whole question of male donation of nutrients to the female must await the results of experiments currently in progress.

Male discrimination in favour of large females would obviously make sense if large females are more fecund. A further precondition for the evolution of such mate discrimination is that the males are unable to "titrate" their donations (whether of sperm or nutrients) so that they match the female's size. We are currently exploring this issue, but whatever the outcome, there is good evidence that large females are more fecund (Butlin and Day, 1985). Given this, it seems inevitable that a male preference for larger females would be strongly favoured over evolutionary time.

Acknowledgements This work was carried out while K. D. Pitafi was on study leave from the Zoology Department, University of Sindh. K. D. Pitafi was supported by a studentship from the Ministry of Education, Government of Pakistan. We also thank Drs S. P. Foster and F. S. Gilbert for critical comments on the manuscript.

\section{REFERENCE}

ALCOCK, J. (1979). The evolution of intraspecific diversity in mate reproductive strategies in some bees and wasps. In Blum, M. S. and Blum, N. A. (eds) Sexual Selection and Reproductive Competition in Insects, Academic Press, New York, pp. 381-402. 
ARAK, A. (1983). Sexual selection by male-male competition in natterjack toad choruses. Nature, 306, 261-262.

BALDWIN, F. T. AND BRYANT, E. H. (1981). Effect of size upon mating performance within geographic strains of the housefly Musca domestica. Evolution, 35, 1134-1141.

BORGIA, G. (1982). Experimental changes in resource structure and male density: size-related differences in mating success among male Scatophaga stercoraria. Evolution, 36, 307-315.

BUTLIN, R. K. AND DAY, T. H. (1985). Adult size, longevity and fecundity in the seaweed fly, Coelopa frigida. Heredity, 54, $107-110$

BUTLIN, R. K., READ, I, L. AND DAY, T. H. (1982). The effects of a chromosomal inversion on adult size and male mating success in the seaweed fly, Coelopa frigida. Heredity, 49, $51-62$.

COOKE, F. AND DAVIES, J. C. (1983). Assortative mating, mate choice and reproductive fitness in snow geese. In Bateson, P. (ed.) Mate Choice, Cambridge University Press, Cambridge, pp. 279-295.

CROCKER, G. AND DAY, T. H. (1987). An advantage to mate choice in the seaweed fly, Coelopa frigida. Behav. Ecol. Sociobiol., 20, 295-301.

DAVIES, N. B. AND HALlidAY, T. R. (1977). Optimal mate selection in the toad Bufo bufo. Nature, 269, 56-58.

DAY, T. H. AND BUCKLEY, P. A. (1980). Alcohol dehydrogenase polymorphism in the seaweed fly, Coelopa frigida. Biochem. Genet., 18, 727-742.

DAY, T. H. AND BUTLIN, R. K. (1987). Non-random mating in natural populations of the seaweed fly, Coelopa frigida. Heredity, 58, 213-220.

DAY, T. H., MILES, S., PILKINGTON, M. D. AND BUTLIN, R. K. (1987). Differential mating success in populations of seaweed flies (Coelopa frigida). Heredity, 58, 203-212.

DAY, T. H., FOSTER, S. P. AND ENGELHARD, G. (1989). Mating behaviour in seaweed flies (Coelopa frigida). J. Insect. Behav., 3, 105-120.

ENGELHARD, G., FOSTER, S. P. AND DAY, T. H. (1989). Genetic differences in mating success and female choice in seaweed flies (Coelopa frigida). Heredity, 62, 123-131.

GWYNNE, D. T. (1981). Sexual difference theory: mormon crickets show role reversal in mate choice. Science, 213, 779-780.
GWYNNE, D. T. (1982). Mate selection by female katydids (Orthoptera: Tettigoniidae, Conocephalus nigropleurum). Anim. Behav., 30, 734-738.

JOHNSON, L. K. (1982). Sexual selection in a brentid weevil Evolution, 36, 251-262.

McCAUley, D. E, AND WADE, M. J. (1978). Female choice and the mating structure of a natural population of the soldier beetle Chauliognathus pennsylvanicus. Evolution, 32, 771775 .

MCLAIN, D. K. (1982). Density dependent sexual selection and positive phenotypic assortative mating in natural populations of the soldier beetle, Chauliognathus pennsylvanicus. Evolution, 36, 1227-1235.

MANNING, J. T. (1975). Male discrimination and investment in Asellus aquaticus (L) and A. meridianus racovitsza (Crustacea: Isopoda). Behaviour, 55, 1-14.

MONCLUS, M. AND PROVOSTI, A. (1971). The relationship between mating speed and wing length in Drosophila subobscura. Evolution, 25, 214-217.

OTRONEN, M. (1984). The effect of differences in body size on the male territorial system of the fly Dryomyza anilis. Anim. Behav., 32, 882-890.

PARTRIDGE, L., HOFFMANN, A. AND JONES, J. S. (1987a). Male size and mating success in Drosophila melanogaster and D. pseudoobscura under field conditions. Anim. Behav., 35 , 468-476.

PARTRIDGE, L., EWING, A. AND CHANDLER, A. (1987b). Male size and mating success in Drosophila melanogaster: The roles of male and female behaviour. Anim. Behav., 35, 555-562.

SOKAL, R. R. AND ROHLF, F. J. (1981). Biometry, 2nd edn. Freeman and $C o$., San Francisco.

THORNHILL, R. (1980). Sexual selection within mating swarms of the lovebug Plecia nearctica (Diptera: Bibionidae). Anim. Behav., 28, 405-412.

TRIVERS, R. L. (1972). Parental investment and sexual selection. In Campbell, B. (ed.) Sexual Selection and the Descent of Man 1871-1971, Heinemann, London, pp. 136-179. 